Cold spraying technology is a method to obtain coating by the high-speed collision of particles with the substrate through supersonic $(300-1200 \mathrm{~m} / \mathrm{s})$ propulsion gas. The deposition process is mainly mechanical bonding, which has attracted more and more attention in engineering applications. The critical component of a cold spraying system is the nozzle. The performance of the nozzle directly affects the quality of the material surface coating. Therefore, the discussion of the nozzle is of great significance. At present, there are many examples of cold spraying single-channel nozzles in engineering, but there are few reports about multi-channel cold spraying nozzles. This paper explores and studies the multi-channel cold spraying nozzle, designs a special three internal channel nozzle, and adopts a $90^{\circ}$ angle in the divergent section of the nozzle. When spraying in a small area, the nozzle with angle has apparent advantages for spraying more areas. The powder injection pressure, particle size, recovery coefficient, and internal channel position are analyzed, which affect the particle trajectory. Combined with these factors, the multi-channel nozzle is optimized and improved to solve the problem of particle collision with the inner wall of the nozzle. Finally, the technological parameters of aluminum, titanium, copper, nickel, magnesium, and zinc powders are preliminarily studied using the multi-channel nozzle. The results show that the multi-channel nozzle meets the critical velocity requirements of copper, magnesium, and zinc powder spraying in the homogeneous (powder and matrix are the same material) and aluminum powder spraying in the case of heterogeneous (powder and matrix are different materials), the multi-channel nozzle has a sound engineering application prospect and provides a specific reference for relevant technicians

Keywords: cold spraying technology, multi-channel nozzle, particle trajectory, particle collision, critical velocity

\section{RESEARCH ON STRUCTURE AND TECHNOLOGICAL PARAMETERS OF MULTI- CHANNEL COLD SPRAYING NOZZLE}

\author{
Wenjie $\mathrm{Hu}$ \\ Corresponding author \\ Postgraduate Student
} Department of Aeronautics and Astronautics* Lecturer Department of Aeronautics and Astronautics Nanchang Institute of Technology No. 901 Yingxiong ave., Nanchang, Jiangxi Province, China E-mail: huwjie30@gmail.com

K un T an

Postgraduate Student Department of Aeronautics and Astronautics* Sergii Markovych $\mathrm{PhD}$, Professor, Deputy Rector for Innovation* Tingting Cao Master, Deputy Director Department of Aircraft Manufacture Engineering Nanchang Hangkong University No. 696 Fenghe South ave., Nanchang, Jiangxi Province, China

*National Aerospace University «Kharkiv Aviation Institute» Chkalova str., 17, Kharkiv, Ukraine, 61070
Received date 27.08.2021 Accepted date 13.10.2021 Published date 29.10.2021
How to Cite: Hu, W., Tan, K., Markovych, S., Cao, T. (2021). Research on structure and technological parameters of multi-channel cold spraying nozzle. Eastern-European Journal of Enterprise Technologies, 5 (1 (113)), 6-14. doi: https://doi.org/ 10.15587/1729-4061.2021.242707

\section{Introduction}

In the early years, global industrial production faced wear, corrosion, and surface oxidation, resulting in serious energy consumption and material waste. Therefore, how to improve the wear resistance and corrosion properties of parts surface has always been a topic discussed by researchers. The use of effective surface treatment technology is the key to improve the service life of parts. Over the years, many traditional surface technologies have been derived [1]. Based on the principle and characteristics, it is usually called thermal spraying technology. Because the thermal spraying process needs heating, spraying materials will appear high-temperature dissolution, high-temperature oxidation, gas evapora- tion, and other defects, resulting in uneven coating formation, porosity, enormous thermal stress in the matrix and other problems. As a result, the emergence of cold spraying technology effectively solves the defects and problems in the thermal spraying process.

Cold spray technology (CS) is different from traditional surface technology, first developed in the mid-1980s [2]. High or low pressure (less than $1 \mathrm{MPa}$ ) gas passes through the nozzle to obtain a supersonic velocity. Supersonic gas pushes particles to impact and plastically deform on the substrate. The deformation process of the surface $[3,4]$, and deposits a uniform thin coating [5-7], mainly applied in surface protection [8], recovery coating, and additive manufacturing [9]. Compared with thermal spraying $[10,11], \mathrm{CS}$ is carrying out 
at a lower temperature, solid powders are rarely oxidizing, and the phenomenon of grain growth is hard to occur. For example, aviation titanium materials are prone to high-temperature oxidation, so metallurgy is complex and has high manufacturing costs. CS can solve these problems well [12]. Hence, scientific research on cold spraying technology is needed to do.

Because of the advantages of CS [13], it expands and makes up for the defects in the field of thermal spraying. Therefore, it has an optimistic prospect and market. In recent years, a lot of researchers [14-16] have been interested in CS. Moreover, more and more cold spraying institutions in the world are founded [17]. For the nozzle structure, the outlet of the nozzle is a mainly circular section, but there is also a square or oval nozzle because of special application occasions [18]. However, there is almost no relevant research on the multi-channel rectangular nozzle. Therefore, this study on multi-channel spraying will provide a new idea and theoretical guidance for the surface coating field.

\section{Literature review and problem statement}

The critical core component of the cold spraying system is the nozzle. Since the early nozzle structure comes from the rocket tail nozzle, most cold spraying nozzles adopt a circular section [19]. In recent years, researchers have studied different types of nozzles for different applications. However, most researchers focus on straight line nozzles (Connecting lines from nozzle inlet to nozzle outlet center). In paper [20] it was proposed a nozzle that can adjust the powder feeding position to improve the deposition efficiency of powder and increase the particle temperature. The powder is mixed in the early stage of the divergent nozzle section to adjust the contact time between powder and fluid. A higher temperature is transmitted to the powder material to obtain the required coating. All of these nozzles are limited by limited space. Therefore, it is necessary to develop a cold spraying nozzle that can meet small space needs and convenient operation. In addition, the circular nozzle is inefficient for small rotating parts in practical engineering applications, and the rectangular section nozzle can reflect its advantages [18]. Hence, it is necessary for the square nozzle with a $90^{\circ}$ angle to research.

The powder injection port of the cold spraying nozzle will affect the airflow and affect the powder flow trajectory. The work [21] presents the straight nozzle with the same diameter as the outlet. Although the airflow speed has been improved and powder diffusion has been prevented since the movement track of powder particles has not been studied, the powder may collide with the inner wall of the outlet. The literature [22] presents a hand-held CS gun and the work [23] researched a short nozzle with a total length of less than $70 \mathrm{~mm}$. It solves the problem that the length is too large to be convenient for spraying, but it can still be further optimized if the diverging section is designed at $90^{\circ}$. The work [24] presents a stepped circle shape, mainly considering the convenience of processing. The fluid analysis results show that the maximum powder velocity is not at the nozzle outlet but the throat, and the length of the nozzle still limits further application. The work [25] solved the problem of pressure transient imbalance during powder injection but increased the processing difficulty and production cost.

A way to overcome these difficulties can be to design the divergence section into $90^{\circ}$. The work [26] presents the results of the airflow trajectory of the three channels. The parameter field from the nozzle to the substrate is obtained, but the airflow in The nozzle is not uniform, which leads to The low application range of powder particles. This may be because the transient pressure is caused by the pressure of the powder injection port, and the pressure of the gas inlet is unbalanced. The authors suggest that the solution reduces the pressure in the internal channel where the powder is injected. The author has made a preliminary study on the nozzle with angle, but the too-long divergence of the nozzle still limits the spray area and is challenging to operate [27], so the divergence length needs to be further shortened. All this suggests that it is advisable to research multi-channel cold spraying nozzles.

\section{The aim and objectives of the study}

The study aims to develop a multi-channel cold spraying nozzle suitable for spraying various powder materials.

To achieve this aim, the following objectives are accomplished:

- the powder injected before the throat was discussed, and the influencing factors were studied;

- the powders' application was studied using multi-channel nozzles, and the technological parameters of standard metal materials (nickel, titanium, copper, aluminum, magnesium, and zinc) were analyzed.

\section{Materials and method}

\section{1. Numerical simulation method}

The SolidWorks /Flow Simulation module is used for numerical simulation. The boundary conditions are as follows: turbulence's influence is considered (turbulence intensity $2 \%$, and the inner wall conditions are adiabatic and smooth). Nitrogen $\left(\mathrm{N}_{2}\right)$ was selected as propelling gas. The internal cavity and excludes the internal non-flowing area are selected. The inlet of the contraction section was selected as the pressure inlet $(4.5-5.5 \mathrm{MPa})$, the initial temperature of the gas is $500 \mathrm{~K}$ to $1000 \mathrm{~K}$, and the outlet of the expansion section was set as the pressure outlet, and it is equal to one atmosphere.

\section{2. Multi-channel nozzle preparation method}

Due to the lack of literature on the rectangular nozzle, the CFD method is used to discuss the situation of the singlechannel nozzle when the powder inlet is set before the compression of the nozzle throat. The author uses the optimized single-channel rectangular section nozzle (the throat chamfer radius is $26 \mathrm{~mm}$, the spraying distance is $13 \mathrm{~mm}$, and the expansion section length is $12 \mathrm{~mm}$ ) to discuss the multi-channel nozzle further. As shown in Fig. 1, if the powder injection port is set in the diffusion section area, the particles meet the requirements of single-channel spraying, but the length of divergence is suitable for powder acceleration.

Hence, this paper discussed that the powder injection port is set in front of the throat to make powder further acceleration. At this time, multiple channels need to be considered to change the particle trajectory to avoid the collision between the particles (nickel, titanium, copper, aluminum, magnesium, and zinc) and the nozzle section divergence's inner wall. The technological parameters were studied as the standard with impact velocity [28] or critical velocity [29]. 


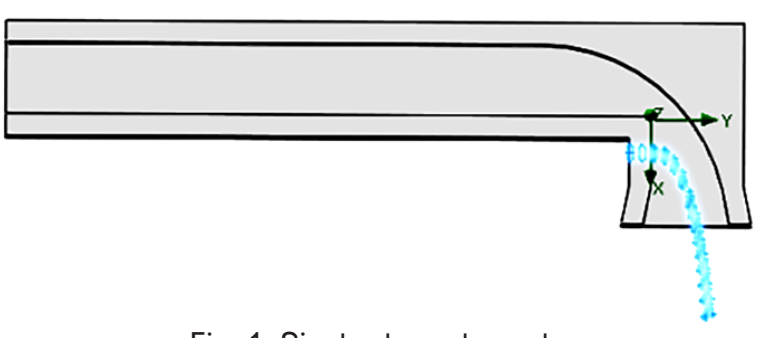

Fig. 1. Single channel nozzle

To facilitate the understanding of multi-channel nozzle, this paper defines some keywords based on Fig. 2: Internal part $1(M)$, Internal part $2(N)$, Internal channel $1(U)$, Internal channel $2(V)$, Internal channel $3(W)$. It should note that $M$ and $N$ are not final optimized structures and need further discussion. $U, V$, and $W$ also change with the optimization of $M$ and $N$.

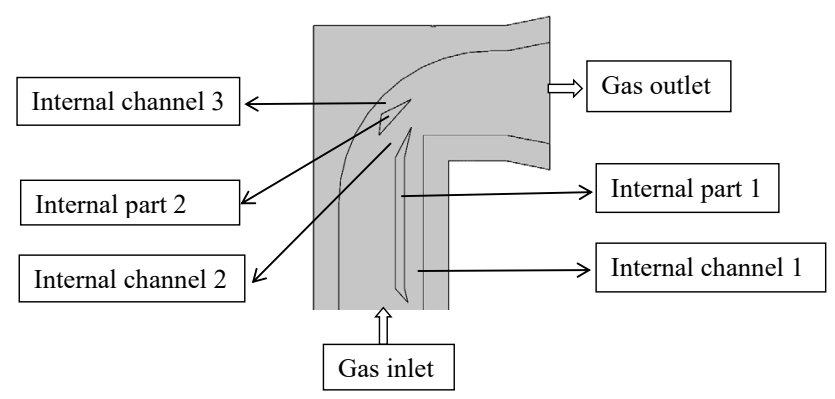

Fig. 2. Initial model of multi-channel nozzle

The optimal structure can be predicted by numerical simulation method to avoid the waste of resources caused by direct processing.

\section{Results of Particle trajectory in multi-channel cold spraying nozzle}

\section{1. Multi-channel nozzle results}

The collision between particles and the inner wall of the nozzle divergent section is mainly affected by the posi- tion of $M$, recovery coefficient, particle size [30], nozzle material [31], and inject powder pressure. The influence position of $M$ is shown in Fig. 3, and its parameters are: $A$ (Fig. $10, b$ ) of $M$ is higher than $B$, the inlet pressure is $5 \mathrm{MPa}$, the temperature of $\mathrm{N}_{2}$ is $600 \mathrm{~K}$, the injection pressure is $3.1 \mathrm{MPa}$, and particle sizes are $10 \mu \mathrm{m}, 20 \mu \mathrm{m}, 30 \mu \mathrm{m}$, $40 \mu \mathrm{m}$, and $50 \mu \mathrm{m}$ respectively. Maintain the inlet pressure of $5 \mathrm{MPa}$, the temperature of $600 \mathrm{~K}$ and the particle size of 10 microns, and the particle trajectory of different injection pressures (3.1 MPa, 3.3 MPa, 3.4 MPa, 3.6 MPa, and $4 \mathrm{MPa}$ ) was shown in Fig. 4.

It can be seen from Fig. 3, 4 that particle size and powder injection pressure have little influence on particle trajectory, and particles are in contact with the inner wall of the nozzle. Therefore, the structure needs to be further adjusted. The inner passage is flush with the outlet (point $A$ and point $B$ are of equal height), as shown in Fig. 5.

Fig. 5, 6 show that the particle trajectory can be improved by improving point A's position and recovery coefficient, but it is still not ideal. Therefore, in the case of multiple internal channels, reducing the position and recovery coefficient of point $A$ by changing the particle diameter and powder injection port pressure alone cannot solve the problem of contact between powder and the inner wall of the nozzle.

Based on the above problems, consider adding another channel to solve. Since particles are mainly affected by drag forces in the fluid, this paper assumes that the powder is spherical particles with smooth surfaces (Fig. 7, $a$ ), and the aerodynamic drag force formula is shown in (1), ignoring the particle gravity, the main force channels $U$ and $V$ of particles are represented by 1 and 3 respectively, and the force direction 2 is the resultant direction. The force analysis diagram is shown in Fig. 7, $b$, when the particle force direction of $V$ is horizontal, the particle trajectory can be improved from force 1 direction to 2 direction.

$$
F=\frac{1}{2} C_{D} \rho_{g}\left(v_{g}-v_{p}\right)^{2} S,
$$

where $F$ is the aerodynamic drag force on the particles; $C_{D}$ is the drag coefficient; $\rho_{g}$ is the density of the air flow; $V_{g}$ and $V_{P}$ are gas flow velocity and particle velocity respectively; $S$ is the upwind area of particles.

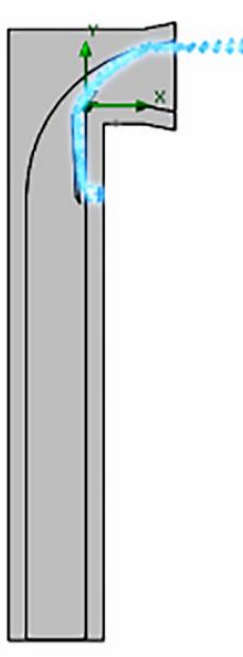

$a$

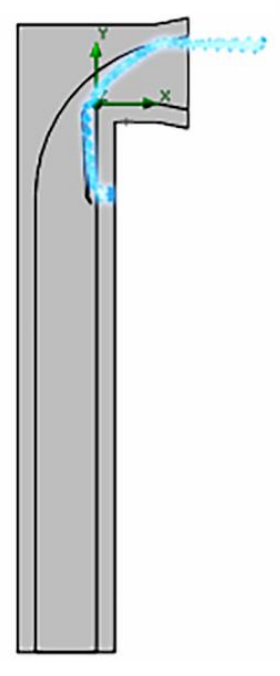

$b$

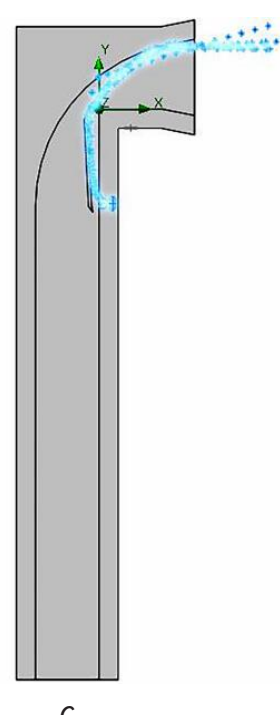

c

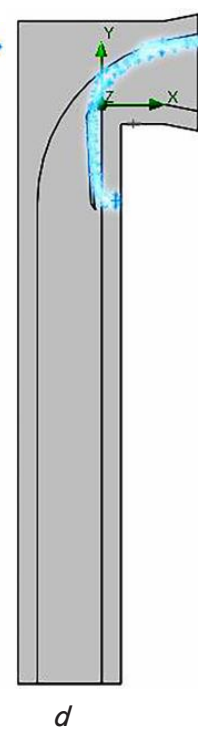

Fig. 3. Particle trajectories of different particle sizes: $a-10 \mu \mathrm{m} ; b-20 \mu \mathrm{m} ; c-30 \mu \mathrm{m} ; d-40 \mu \mathrm{m} ; e-50 \mu \mathrm{m}$ 


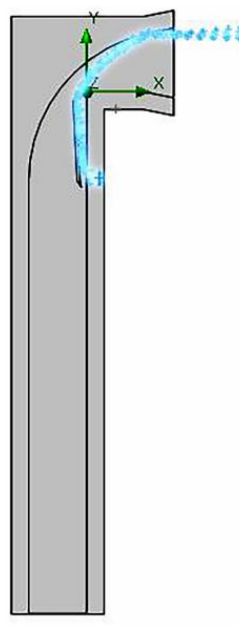

a

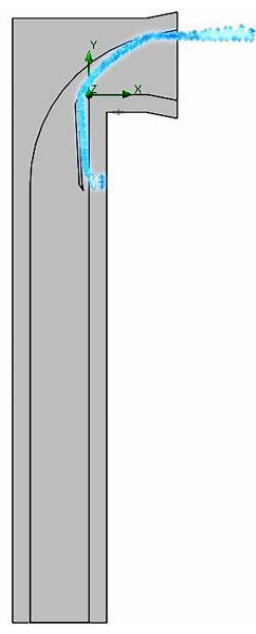

$b$

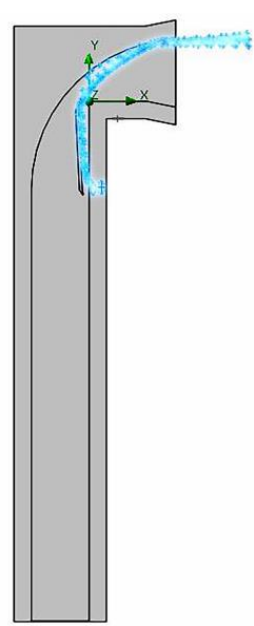

$c$

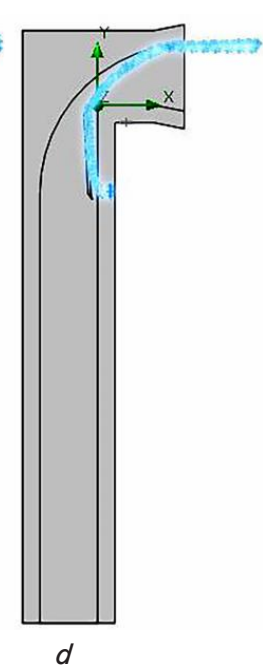

d

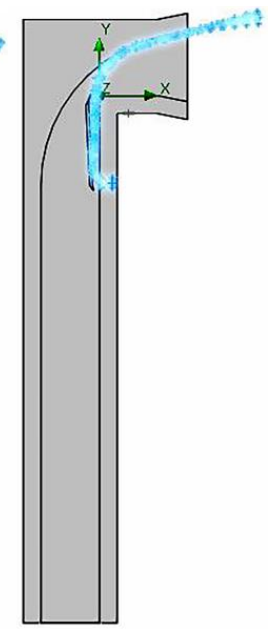

e

Fig. 4. Particle tracks of powder injection ports at different injection pressures: $a-3.1 \mathrm{MPa} ; b-3.3 \mathrm{MPa} ; c-3.4 \mathrm{MPa}$; $d-3.6 \mathrm{MPa}$; e $-4 \mathrm{MPa}$

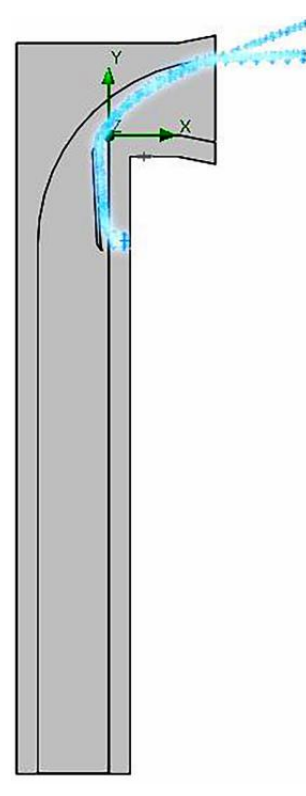

a

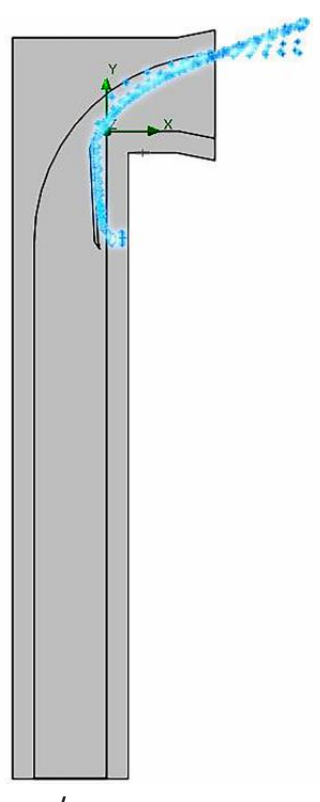

$b$

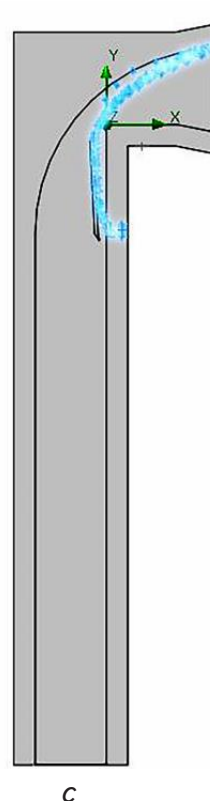

c

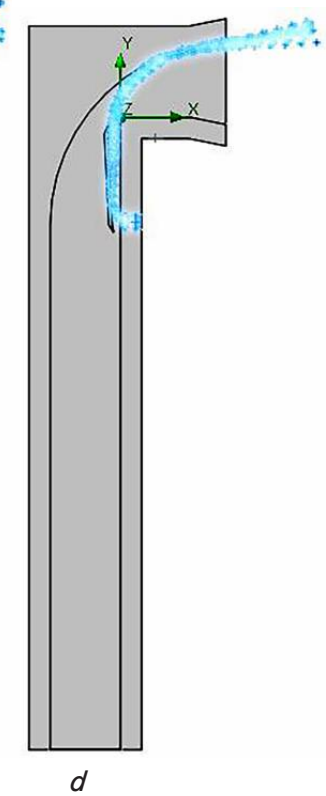

Fig. 5. Particle tracks of different powder injection pressures when $A$ and $B$ are flush: $a-3.4 \mathrm{MPa} ; b-3.6 \mathrm{MPa} ; c-3.8 \mathrm{MPa} d-4 \mathrm{MPa}$

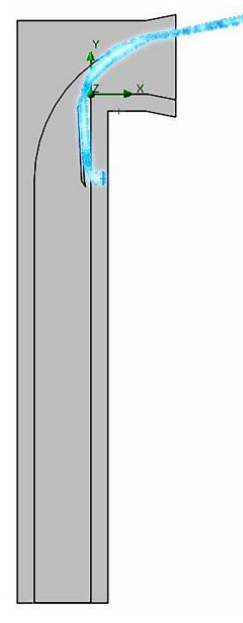

a

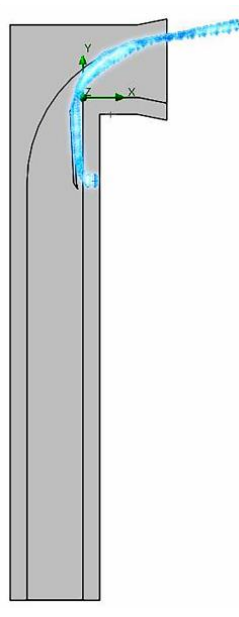

b

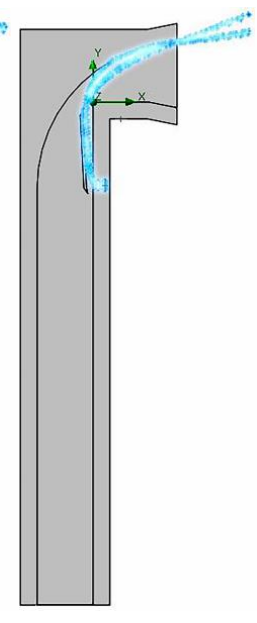

c

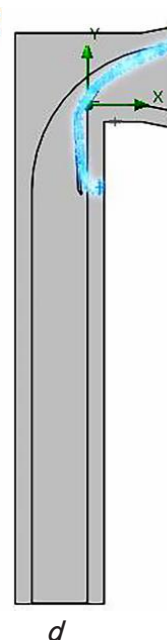

$d$

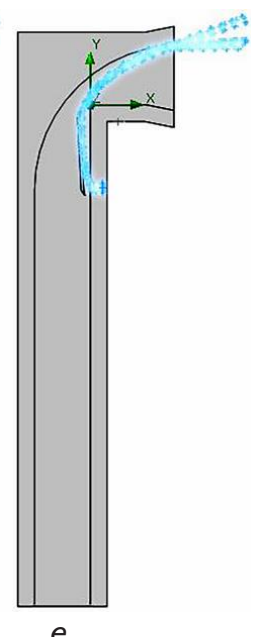

Fig. 6. Particle trajectories with different recovery coefficients: $a-0.2 ; b-0.4 ; c-0.6 ; d-0.8 ; e-1$ 

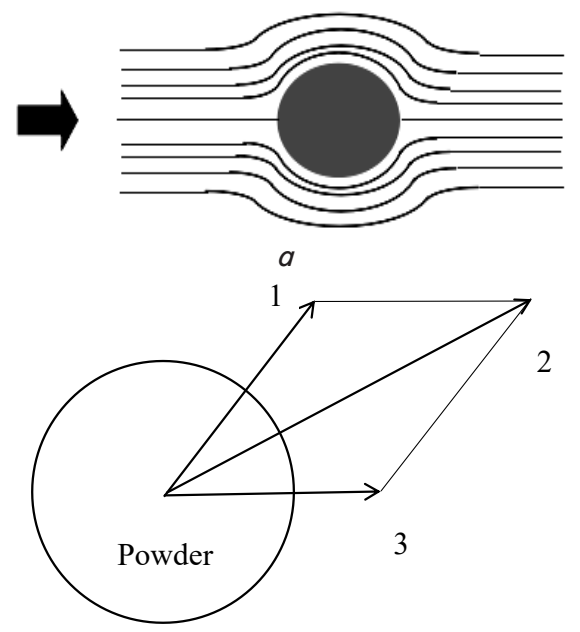

$b$

Fig. 7. Particles are subjected to fluid action: $a$ - the path of a fluid through a particle; $b$ - force analysis diagram of particles in fluid

Further, $N$ was added, and the channels were changed into $U, V$, and $W$. The position of $N$ was optimized to improve the particle trajectory. When the distance between $N$ and $M$ was further optimized to $1.2 \mathrm{~mm}$, the result was relatively ideal, as shown in Fig. 8.
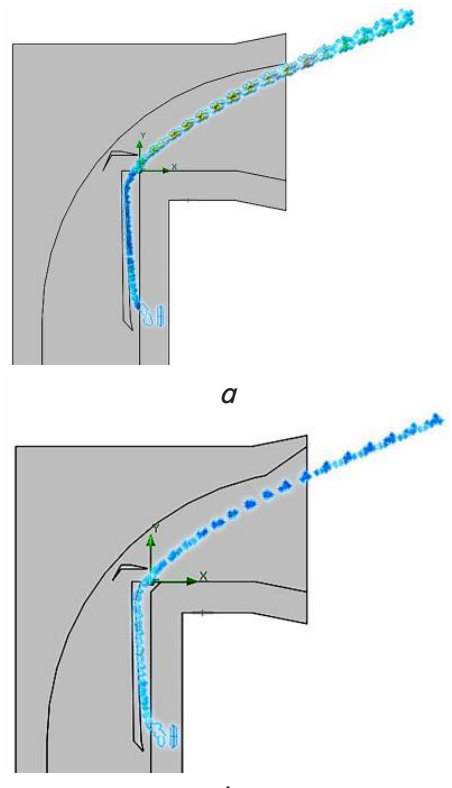

$b$

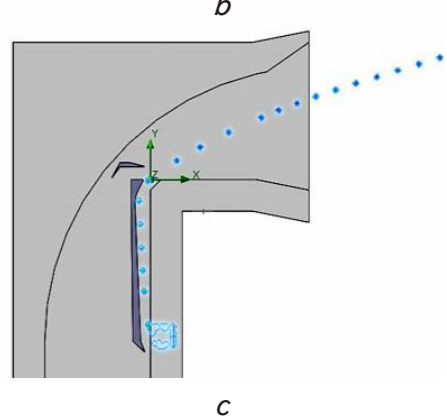

Fig. 8. Distance between $M$ and $N$ components: $a-1.6 \mathrm{~mm}(\mathrm{Al}-10 \mu \mathrm{m})$; $b-1.2 \mathrm{~mm}(\mathrm{Al}-10 \mu \mathrm{m})$; $c-1.2 \mathrm{~mm}(\mathrm{Al}-15 \mu \mathrm{m})$
The specific parameters are shown in Fig. 9.

\section{2. The technological parameters of common metal} materials

The main factors affecting impact velocity are gas pressure, temperature, and particle diameter [32].

Although the recovery coefficient has little influence on the collision velocity (Table 1), it influences the particle trajectory, as shown in Fig. 10.

Hence, selecting a smaller recovery coefficient is beneficial to the particle trajectory.

According to the numerical simulation results of several common materials (Table 2), particles of different materials have different paths (Fig. 11), and their collision velocities differ significantly.

Magnesium powder with low density has a speed of $576 \mathrm{~m} / \mathrm{s}$ at $600 \mathrm{~K}$.

The velocity of titanium powder can reach $592 \mathrm{~m} / \mathrm{s}$ at the gas temperature of $1000 \mathrm{~K}$, etc.

These results show that the material with lower density can obtain higher impact velocity, while the powder material with higher density can only obtain lower impact velocity, and the temperature has a significant influence on the impact velocity, etc.

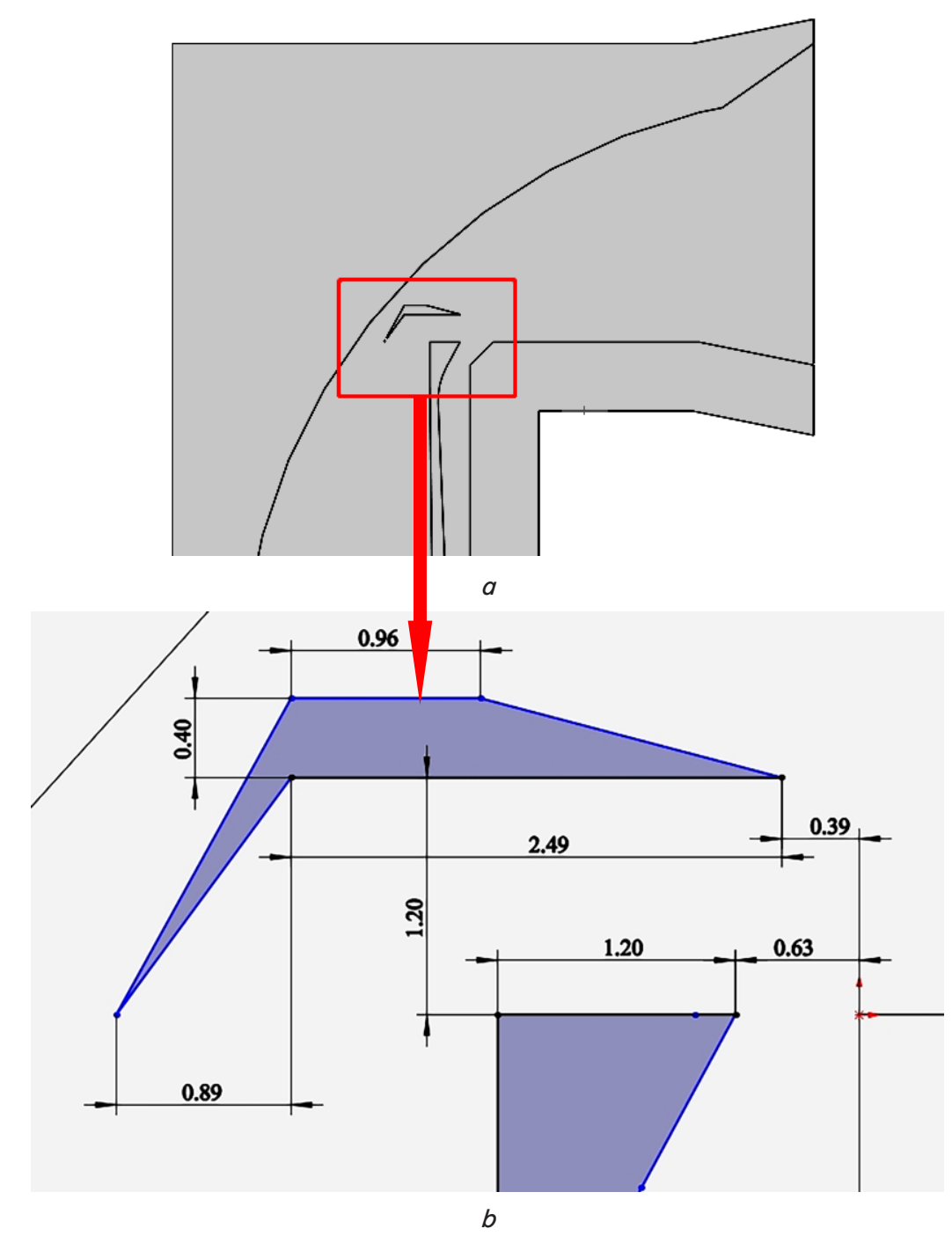

Fig. 9. The specific size after optimization: $a-$ the dimension location of the 3D model; $b$ - detailed dimensions 
Table 1

Numerical simulation parameters and results of aluminum particles

\begin{tabular}{|c|c|c|c|c|c|}
\hline The pressure of $\mathrm{N}_{2}, \mathrm{MPa}$ & The temperature of $\mathrm{N}_{2}, \mathrm{~K}$ & Injection pressure, $\mathrm{MPa}$ & Particle diameter, $\mu \mathrm{m}$ & Recovery coefficient & $V_{\text {impact }} \mathrm{m} / \mathrm{s}$ \\
\hline 5 & 800 & 3 & 10 & 1 & 1 \\
\hline 5 & 800 & 2.55 & 15 & 1 & 535 \\
\hline 5 & 800 & 2.55 & 20 & 1 & 482 \\
\hline 5 & 700 & 3 & 10 & 1 & 580 \\
\hline 5 & 900 & 3 & 10 & 0.7 & 635 \\
\hline 5 & 900 & 3.2 & 10 & 0.4 & 635 \\
\hline 5 & 900 & 3.2 & 10 & 0.2 & 633 \\
\hline 5 & 900 & 3.2 & 10 & 0.7 & 623 \\
\hline 4.5 & 900 & 2.9 & 10 & 0.7 & 589 \\
\hline 5.5 & 900 & 3 & & & \\
\hline
\end{tabular}

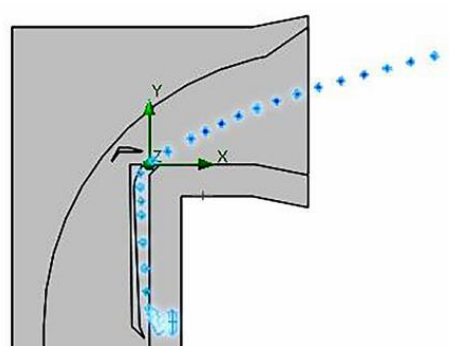

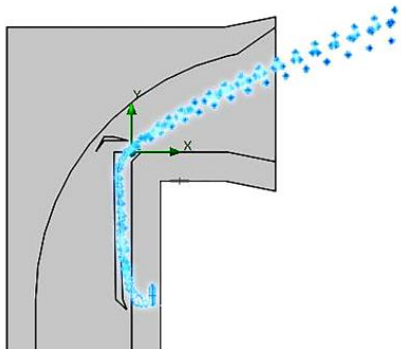

$b$

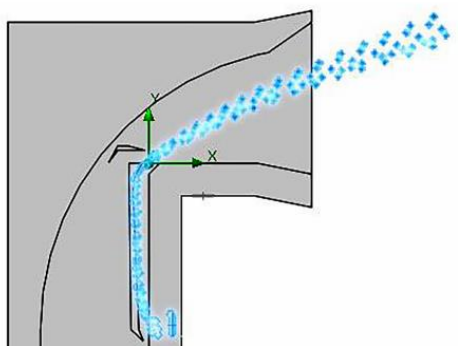

Fig. 10. Trajectory diagram of different particle sizes under recovery coefficient $e=0.1$ : $a-D=10 \mu \mathrm{m} ; b-D=30 \mu \mathrm{m} ; c-D=50 \mu \mathrm{m}$

Table 2

Technological parameters and results of other common materials

\begin{tabular}{|c|c|c|c|c|c|c|c|}
\hline Materials & $\begin{array}{c}\text { The pressure } \\
\text { of } \mathrm{N}_{2}, \mathrm{MPa}\end{array}$ & $\begin{array}{c}\text { The tempera- } \\
\text { ture of } \mathrm{N}_{2}, \mathrm{~K}\end{array}$ & $\begin{array}{c}\text { Injection } \\
\text { pressure, MPa }\end{array}$ & $\begin{array}{c}\text { Particle } \\
\text { diameter, } \mu \mathrm{m}\end{array}$ & $\begin{array}{c}\text { Recovery } \\
\text { coefficient }\end{array}$ & $V_{\text {impact }}, \mathrm{m} / \mathrm{s}$ & $T_{\text {impact }}, \mathrm{K}$ \\
\hline $\mathrm{Ti}$ & 5 & 1000 & 2.7 & 10 & 0.1 & 592 & 808 \\
\hline $\mathrm{Cu}$ & 5 & 900 & 2.7 & 10 & 0.1 & 485 & 726 \\
\hline $\mathrm{Ni}$ & 5 & 1000 & 2.7 & 10 & 0.1 & 500 & 835 \\
\hline $\mathrm{Mg}$ & 5 & 600 & 2.9 & 10 & 0.1 & 576 & 460 \\
\hline $\mathrm{Zn}$ & 5 & 500 & 2.7 & 10 & 0.1 & 416 & 381 \\
\hline
\end{tabular}

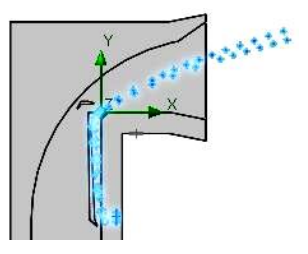

$a$

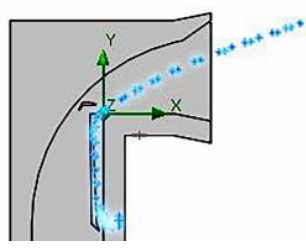

b

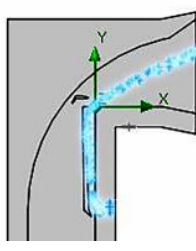

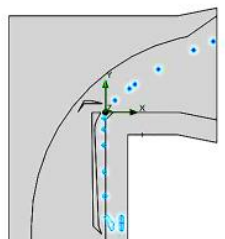

d

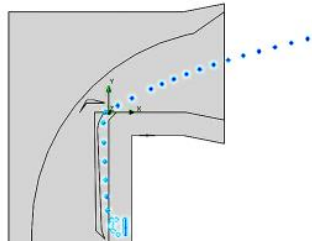

e

Fig. 11. Particle trajectories of different materials: $a-\mathrm{Ti} ; b-\mathrm{Cu} ; c-\mathrm{Ni} ; d-\mathrm{Mg} ; e-\mathrm{Zn}$

Comparing the collision velocity with the critical velocity is the standard to judge whether the powder can be deposited.

The critical velocities of nickel (Ni), titanium (Ti), copper $(\mathrm{Cu})$, aluminum $(\mathrm{Al})$, magnesium $(\mathrm{Mg})$, and zinc $(\mathrm{Zn})$ can be obtained by theoretical calculation equation (2). The results are summarized in Table 3 :

$$
V_{\text {crit }}=\sqrt{C_{P}\left(0.7 T_{m}-T_{i}\right)},
$$

where $C_{p}$ is the specific heat; $T_{m}$ is the melting point; $T_{i}$ is impact temperature. As the melting point of different metal materials is different, the value range of temperature data in Table 3 is not more than $0.7 T_{m}$. For example, the melting point of aluminum is $916 \mathrm{~K}$, hence, the maximum temperature is $600 \mathrm{~K}$. 
Table 3

Common metal critical values at different temperatures by (2)

\begin{tabular}{|c|c|c|c|c|c|c|c|c|c|c|}
\hline \multicolumn{2}{|c|}{ Powder parameters $\quad$ Temperature, $\mathrm{K}$} & 400 & 500 & 600 & 700 & 800 & 900 & 1000 & 1100 & 1200 \\
\hline \multirow{3}{*}{$\mathrm{Ni}$} & Maximum speed, m/s & - & - & - & - & - & 533 & 550 & 570 & 585 \\
\hline & Critical speed, m/s & - & - & - & - & - & 587 & 574 & 564 & 552 \\
\hline & Whether deposition? (yes or no) & - & - & - & - & - & no & no & yes & yes \\
\hline \multirow{3}{*}{$\mathrm{Ti}$} & Maximum speed, $\mathrm{m} / \mathrm{s}$ & - & - & - & 587 & 615 & 640 & 658 & 680 & 698 \\
\hline & Critical speed, $\mathrm{m} / \mathrm{s}$ & - & - & - & 632 & 619 & 605 & 590 & 576 & 560 \\
\hline & Whether deposition? (yes or no) & - & - & - & no & no & yes & yes & yes & yes \\
\hline \multirow{3}{*}{$\mathrm{Cu}$} & Maximum speed, m/s & - & - & 464 & 488 & 512 & 532 & - & - & - \\
\hline & Critical speed, $\mathrm{m} / \mathrm{s}$ & - & - & 480 & 467 & 452 & 437 & - & - & - \\
\hline & Whether deposition? (yes or no) & - & - & no & yes & yes & yes & - & - & - \\
\hline \multirow{3}{*}{$\mathrm{Al}$} & Maximum speed, m/s & 525 & 568 & 608 & - & - & - & - & - & - \\
\hline & Critical speed, $\mathrm{m} / \mathrm{s}$ & 570 & 544 & 517 & - & - & - & - & - & - \\
\hline & Whether deposition? (yes or no) & no & yes & yes & - & - & - & - & - & - \\
\hline \multirow{3}{*}{$\mathrm{Mg}$} & Maximum speed, $\mathrm{m} / \mathrm{s}$ & 562 & 608 & 652 & - & - & - & - & - & - \\
\hline & Critical speed, $\mathrm{m} / \mathrm{s}$ & 630 & 600 & 570 & - & - & - & - & - & - \\
\hline & Whether deposition? (yes or no) & no & yes & yes & - & - & - & - & - & - \\
\hline \multirow{3}{*}{$\mathrm{Zn}$} & Maximum speed, $\mathrm{m} / \mathrm{s}$ & 432 & 463 & - & - & - & - & - & - & - \\
\hline & Critical speed, $\mathrm{m} / \mathrm{s}$ & 299 & 274 & - & - & - & - & - & - & - \\
\hline & Whether deposition? (yes or no) & yes & yes & - & - & - & - & - & - & - \\
\hline
\end{tabular}

\section{Discussion on the result of multi-channel cold spray} nozzle and technological parameters

In this paper, the powder track and technological parameters of powders inside the multi-channel nozzle with $90^{\circ}$ are analyzed, it is feasible to apply the multi-channel nozzle to spray typical metal powder. The influence analysis of particle trajectory, include powder injection pressure, Inlet gas pressure, and temperature, particle size, Recovery coefficient, has revealed the following:

- due to high-pressure cold spraying, if the powder injection pressure is too small, it is difficult to inject into the internal channel of the nozzle. If the powder injection pressure is too enormous, there will be different degrees of rebound according to the recovery coefficient of $M$ material. Therefore, it is necessary to adjust the powder injection pressure reasonably; Inlet propulsion gas pressure and temperature mainly affect fluid velocity and then affect particle acceleration, so parameters need to be adjusted according to practical engineering applications; Particle size affects particle acceleration, as shown in Fig. 10, $a, b$. The larger particle trajectory is upward, mainly because the force on direction 1 (Fig. 7, $b$ ) is greater. Therefore, to avoid particle contact with the inner wall, the smaller particle size should be selected as far as possible for the multi-channel nozzle with $90^{\circ}$. Distance between $M$ and $N$ affects the particle trajectory, as shown in Fig. 9. When the distance is larger, the particle trajectory is upward, mainly because the force on direction 3 (Fig. 7, b) is smaller, resulting in direction 2 of the resultant force being more upward;

- as Tables 2, 3 shown, the process analysis of typical metal powders under the condition that the matrix and powder materials are the same, the particles that meet the critical velocity requirements include copper, magnesium, and zinc. When the matrix and powder materials have different properties, aluminum (aluminum collides with titanium) can meet the requirements of critical velocity [33], which has a broad application prospect.

Compared with existing single-channel nozzles, multichannel nozzles with $90^{\circ}$ have advantages in limited space spraying because in practical engineering applications, only the divergence length of the nozzle is considered, and the operation is more convenient. However, this paper only preliminarily proposed the feasibility of multi-channel nozzle application in spraying. For the $M$ and $N$ structures in Fig. 9, if processing, cost, and other factors are taken into further consideration, their structures need to be further optimized. As shown in Fig. 10, many sharp points need to be filleted, etc. Alternatively, the later research can consider further optimization of multiple factors by using functional relations.

Because of the technological parameters, this paper only discusses the several common kinds of metal powder and other materials can be discussed further in the future, because of the influence of temperature on the nozzle internal fluid velocity is larger, thus affect powder particle velocity, it is necessary to take into account the manufacturing materials of the nozzle, such as titanium and nickel powder can raise the temperature further improve powder outlet velocity.

The $90^{\circ}$ multi-channel nozzle was presented in this paper, which is an innovative structure, and the difficulty of multi-channel nozzle research lies in the commonality of powder, after all, many factors affecting the movement trajectory of powders. The future trend is to establish a perfect mathematical method for the multi-factor or experimental method to improve the multi-channel nozzle. 


\section{Conclusions}

1. The research of cold spraying nozzle is an interesting point for science researchers. According to different application occasions, different nozzles are designed and manufactured. Some special applications need to study special nozzles. In order to further facilitate spraying, a three-dimensional model of the multi-channel nozzle is established in this paper, and the influencing factors of particle trajectory are discussed through the fluid module. For the multi-channel cold spraying nozzle with a divergence section of $90^{\circ}$, when the powder injection port is located before the throat, multiple fluid internal channels need to be set in the throat to avoid the contact between particles and the inner wall of the divergent section of the nozzle. Parameters influence particle trajectory such as powder injection port pressure, particle size, recovery coefficient, etc.

2. Multi-channel cold spraying nozzle with $90^{\circ}$ angle will be more convenient to use, such as some corners, internal areas, etc. Proper optimization of the nozzle, which can meet a variety of powder material (aluminum, copper, magnesium, and zinc) spraying, has a good application prospect.

\section{Acknowledgment}

The authors would like to thank the China Scholarship Council for its support (no. 202008100011).

\section{References}

1. Goyal, T., Sidhu, T. S., Walia, R. S. (2013). An overview on cold spray process over competitive technologies for electro-technical applications. Presentation made at The National Conference on Advancements and Futuristic Trends in Mechanical and Materials Engineering, YCoE, Talwandi Sabo.

2. Oyinbo, S. T., Jen, T.-C. (2019). A comparative review on cold gas dynamic spraying processes and technologies. Manufacturing Review, 6, 25. doi: https://doi.org/10.1051/mfreview/2019023

3. Moridi, A., Hassani-Gangaraj, S. M., Guagliano, M., Dao, M. (2014). Cold spray coating: review of material systems and future perspectives. Surface Engineering, 30 (6), 369-395. doi: https://doi.org/10.1179/1743294414y.0000000270

4. Marrocco, T., McCartney, D. G., Shipway, P. H., Sturgeon, A. J. (2006). Production of Titanium Deposits by Cold-Gas Dynamic Spray: Numerical Modeling and Experimental Characterization. Journal of Thermal Spray Technology, 15 (2), 263-272. doi: https://doi.org/10.1361/105996306x108219

5. Assadi, H., Gärtner, F., Stoltenhoff, T., Kreye, H. (2003). Bonding mechanism in cold gas spraying. Acta Materialia, 51 (15), 4379-4394. doi: https://doi.org/10.1016/s1359-6454(03)00274-x

6. Raoelison, R. N., Xie, Y., Sapanathan, T., Planche, M. P., Kromer, R., Costil, S., Langlade, C. (2018). Cold gas dynamic spray technology: A comprehensive review of processing conditions for various technological developments till to date. Additive Manufacturing, 19, 134-159. doi: https://doi.org/10.1016/j.addma.2017.07.001

7. Singh, H., Sidhu, T. S., Kalsi, S. B. S. (2012). Cold spray technology: future of coating deposition processes. Frattura Ed Integrità Strutturale, 6 (22), 69-84. doi: https://doi.org/10.3221/igf-esis.22.08

8. Sun, W., Tan, A. W. Y., Marinescu, I., Toh, W. Q., Liu, E. (2017). Adhesion, tribological and corrosion properties of cold-sprayed CoCrMo and $\mathrm{Ti}_{6} \mathrm{Al}_{4} \mathrm{~V}$ coatings on 6061-T651 Al alloy. Surface and Coatings Technology, 326, 291-298. doi: https://doi.org/ 10.1016/j.surfcoat.2017.07.062

9. MacDonald, D., Fernández, R., Delloro, F., Jodoin, B. (2016). Cold Spraying of Armstrong Process Titanium Powder for Additive Manufacturing. Journal of Thermal Spray Technology, 26 (4), 598-609. doi: https://doi.org/10.1007/s11666-016-0489-2

10. Zhang, J. H., Sun, R. (2014). Research progress of laser cladding on titanium alloy surface. Material review, 28 (6), 89-93.

11. Pan, X. Y., Liang, W. P., Miu, Q., Ren, B. L., Liu, W. (2016). Tribological Behavior of Plasma Chromized Layer on TC21 Alloy at different temperatures. Journal of Nanjing University of Aeronautics \& Astronautics, 48 (1), 35-41. doi: https://doi.org/ 10.16356/j.1005-2615.2016.01.006

12. Hu, W., Markovych, S., Tan, K., Shorinov, O., Cao, T. (2020). Surface repair of aircraft titanium alloy parts by cold spraying technology. Aerospace Technic and Technology, 3, 30-42. doi: https://doi.org/10.32620/aktt.2020.3.04

13. Karthikeyan, J. (2007). The advantages and disadvantages of the cold spray coating process. The Cold Spray Materials Deposition Process, 62-71. doi: https://doi.org/10.1533/9781845693787.1.62

14. Meyer, M., Lupoi, R. (2015). An analysis of the particulate flow in cold spray nozzles. Mechanical Sciences, 6 (2), $127-136$. doi: https://doi.org/10.5194/ms-6-127-2015

15. Cavaliere, P., Silvello, A. (2016). Mechanical properties of cold sprayed titanium and nickel based coatings. Surface Engineering, 32 (9), 670-676. doi: https://doi.org/10.1179/1743294415y.0000000080

16. Chen, Q.-Y., Zou, Y.-L., Chen, X., Bai, X.-B., Ji, G.-C., Yao, H.-L. et. al. (2019). Morphological, structural and mechanical characterization of cold sprayed hydroxyapatite coating. Surface and Coatings Technology, 357, 910-923. doi: https://doi.org/10.1016/ j.surfcoat.2018.10.056

17. Tewes, J. (2013). Advancements in cold Spray. CSAT Summer Meeting. Available at: https://docplayer.net/39787940-Advancements-in-cold-spray.html

18. Zhou, X. L., Zhang, J. S., Wu, X. K. (2011). Advanced Cold Spraying Technology and Application. Machinery Industry Press.

19. Li, Q. (2008). Structure design and optimization of cold spray gun. Shenyang University of Technology. Available at: http://cdmd. cnki.com.cn/article/cdmd-10142-2008203950.htm 
20. Arndt, A., Pyritz, U., Schiewe, H., Ullrich, R. (2008). WO2008084025 - Method and device for the cold-gas spraying of particles having different solidities and/or ductilities. Available at: https://patentscope.wipo.int/search/en/detail. jsf?docId=WO2008084025\&tab=PCTBIBLIO

21. Wu, Z. L. (2011). Numerical simulation research of the internal flow field cold of the spray gun nozzle and structural optimization, Henan Polytechnic University.

22. Irissou, E., Legoux, J.-G., Ryabinin, A. N., Jodoin, B., Moreau, C. (2008). Review on Cold Spray Process and Technology: Part I - Intellectual Property. Journal of Thermal Spray Technology, 17 (4), 495-516. doi: https://doi.org/10.1007/s11666-008-9203-3

23. Li, W.-Y., Li, C.-J. (2005). Optimal Design of a Novel Cold Spray Gun Nozzle at a Limited Space. Journal of Thermal Spray Technology, 14 (3), 391-396. doi: https://doi.org/10.1361/105996305x59404

24. Canales, H., Litvinov, A., Markovych, S., Dolmatov, A. (2014). Calculation of the critical velocity of low pressure cold sprayed materials. Questions of design and production of designs of aircraft, 3, 86-91. URL: http://nbuv.gov.ua/UJRN/Pptvk_2014_3_11

25. Cao, T. T., Yang, Y. X., Hu, W. J. (2021). Pat. No. CN212688180U. The gas path protection device for cold spraying. Available at: https://wenku.baidu.com/view/7f5efcecf8d6195f312b3169a45177232e60e4c8

26. Dolmatov, A. I., Polyviany, S. A. (2021). Interaction of Solid Particles from a Gas Stream with the Surface of a Flat Nozzle. METALLOFIZIKA I NOVEISHIE TEKHNOLOGII, 43 (3), 319-328. doi: https://doi.org/10.15407/mfint.43.03.0319

27. Hu, W. J., Tan, K., Markovych, S., Liu, X. L. (2021). Study of a Cold Spray Nozzle Throat on Acceleration Characteristics via CFD. Journal of Engineering Sciences, 8 (1), F19-F24. doi: https://doi.org/10.21272/jes.2021.8(1).f3

28. Grujicic, M., Zhao, C. L., Tong, C., DeRosset, W. S., Helfritch, D. (2004). Analysis of the impact velocity of powder particles in the cold-gas dynamic-spray process. Materials Science and Engineering: A, 368 (1-2), 222-230. doi: https://doi.org/10.1016/ j.msea.2003.10.312

29. Li, C.-J., Li, W.-Y., Liao, H. (2006). Examination of the Critical Velocity for Deposition of Particles in Cold Spraying. Journal of Thermal Spray Technology, 15 (2), 212-222. doi: https://doi.org/10.1361/105996306x108093

30. Van Steenkiste, T. H., Smith, J. R., Teets, R. E. (2002). Aluminum coatings via kinetic spray with relatively large powder particles. Surface and Coatings Technology, 154 (2-3), 237-252. doi: https://doi.org/10.1016/s0257-8972(02)00018-x

31. Cao, C. C., Li, W. Y., Han, T. P., Yang, X. Y., Xu, Y. X., Hu, K. W. (2019). Simulation study on effect of cold spray nozzle material on particle Acceleration Behavior. Journal of Netshape Forming Engineering, 6 (11), 149-153. Available at: https://global.cnki.net/ $\mathrm{kcms} /$ detail/detail.aspx? filename $=J$ MCX201906023\&dbcode $=$ CJFQ \&dbname $=$ CJFD2019\&v $=$

32. Alhulaifi, A. S., Buck, G. A. (2014). A Simplified Approach for the Determination of Critical Velocity for Cold Spray Processes. Journal of Thermal Spray Technology, 23 (8), 1259-1269. doi: https://doi.org/10.1007/s11666-014-0128-8

33. Yang, Y., Hao, Y., Kong, L. Y., Cui, X. Y., Wu, J., Li, T. F., Xiong, T. Y. (2015). Research on Critical Velocity of Particle during Cold Spray Process. Thermal spray technology, 7 (4), 1-16. Available at: http://61.143.209.103:81/article/detail.aspx?id=6677440126 